\title{
STUDY ON THE INFLUENCE OF USING CIRCUIT TRAINING FOR THE EDUCATION AND DEVELOPMENT OF COORDINATION SKILLS OF U16 HANDBALL PLAYERS
}

\author{
Narcis Cristea-Mic ${ }^{1}$, Lecturer Liana Maria Costea ${ }^{2}$ \\ ${ }^{1}$ National University of Physical Education and Sport, str. Constantin Noica 140, București,cod \\ 060057, \\ 2"1 Decembrie 1918" University of Alba-Iulia, str. Gabriel Bethlen 5, Alba-Iulia, cod \\ $510009, \mathrm{ROU}^{*}$ corresponding author \\ cristeamicnarcis@gmail.com \\ costealiana2005@yahoo.com
}

\begin{abstract}
This study seeks to use complex means (circuit training), which will lead to technical improvements in U16 male handball, along with the development of conditional and coordinating skills.

The sample of the study consisted of two groups of subjects (experimental and control) consisting of 21 and 17 athletes respectively. The selected subjects were handball players from Bucharest Municipal Sports Club - the experimental group, and athletes of the handball team from School Sports Club No. 2 Bucharest - the control group.

The results obtained have shown that the specific means and materials used by us during the application stages of the training of the male handball players, led to the optimization of the technical training by enriching the motor repertoire, the development of conditional and coordinating skills, the consolidation and improvement general and specific motor skills.
\end{abstract}

Keywords: handball, circuit training, coordinating skills, technique.

\section{Introduction}

Today, handball has become an extremely demanding and complex game, which requires players to have high-intensity movements, frequent body contacts, as well as high intensity stamina and strength.

The ingame creativity, coupled with high-speed moves, sudden turns, rapid changes of pace, throwing the ball at high speed while making body contact makes this game very attractive but difficult to play. Thus, players are required to have superior physical, technical and tactical capabilities to overcome all adversities imposed by competitive environments. For these reasons it is recommended that coaches be concerned with developing motor, perceptual and cognitive skills using various means during the process of training.

Thus, a player withwelldeveloped motor skills increases the probability of success in physically challenging situations. This is because players will be better able to analyze, predict or anticipate environmental conditions, and ultimately react more effectively and appropriately (Higgs, 2010). 
The maximum intensity of development of motor skills, especially coordination skills, takes place between the ages of 7-11 and 14-18 years. Performing certain exercises develops the efficiency of the central nervous system, and indirectly increases the level of coordination, which in turn allows for a better movement execution (Cojocari, D., 2014, pp.14-29;Starosta,W., 2006, pp.9-23).

Coordinating capacities serve to form a global movement from partial movements in a consistent and coordinated manner. If these movements are coordinated, we can achieve the highest level of overall coordination (Esfahankalati, A., et.al., 2013, pp. 42-46).

Blumenstein, B., et.al., (2007, pp. 62-67) thinks that these are important during the game of handball since they need to progress from an early age. Especially, coaches working with young players will need to include the development of coordination in their daily workout program.

Thus, a high degree of "handball specific coordination skills" allows the player to execute complex actions at higher and higher speed, and can be applied, for example, when movements are restricted by the actions of the defenders (Starosta,W., 2006, pp. 9-23).

The development of coordination, sensory and perceptual skills has a positive impact on technical abilities, contributing to their development (Dumitru,G., 2011, p. 8).

It is believed that the high level of basic, situational, cognitive and functional motor skills is an important condition for efficient learning, perfecting and successful implementation of new motor structures (Hirtz, P., et.al., 2002, pp. 19-28).

At the basis of a workable execution of the model of the established motor program, there is good coordination, which in turn depends on the correctness of information from analysts (whose role and integrity are decisive).

\section{Matherialsand methods}

We have assumed that the use structures of means for enriching the motor repertoire as well as to strengthen and improve handball skills, can positively influence the specific indicators, for the purpose of learning and developing coordination skills.

The research was carried out over a period of six months, comprising two groups of subjects (experimental and control) consisting of 21 and 17 athletes respectively, members of the male youth teams of Bucharest Municipal Sports Club - the experimental group, and those of School No. 2 Sports Club Bucharest - the control group. During the research we used a set of specific technical training methods of circuit training, which were applied to the experimental group 3 times per week, 15 minutes each, at the beginning of each training session. 
Circuit training 1: 4 alternate jumps on vaulting box, arms swinging upwards; winding run among 4 marking cones, repeat after changing side; 4 lateral jumps over bench with legs apart; 3 pushups with medicine ball touching the chest; running round a cone; lateral movement with side steps among 4 cones; two leg jumping over 4 hurdles; catching a handball with two hands down; forward dribbling among 4 cones with dominant hand; jump shot at goal from the 9-metre area; recovering the ball and returning it to original place by running 4/4; returning to the end of queue by running backward.

Circuit training 2: 5 jumps from beside the bench with legs apart onto the bench; winding run sideways among 4 cones, repeating on other side; throwing 3-kilogram medicinal ball 4 meters away from the chest, recovering the ball and placing it at the throwing point; 4 toe touch crunches on gym mat; catching handball with two hands; dribbling through conesrunning sideways, then repeating with opposing side; dribbling forward among the cones; jump shot at goal from the 9-metre area; recovering the ball and returning to formation.

Circuit training 3: winding run around 2 cones placed in the way;cushioned dive on arms; two leg jumps over 4 succesive cones; turning around a cone;jumps from beside the bench with legs apart onto the bench; winding run around 2 cones placed transversely in the way,repeating on opposite side; catching a handball with two hands; dribbling around 2 cones placed transversely in the way, repeating on opposite side; dribbling with jump shot from the 9metre area; recovering the ball and running back to formation.

The set of tests was selected from the work of Reiman, M., P., et.al., (2009, p.193) with the aim of evaluating speed, agility, multidirectional body control, explosive upper limb force (armspan).

\section{"Pro agility" test (5-10-5)}

- Aim: testing speed in different directions, agility and body control.

- $\quad$ Equipment: 4 cones, stopwatch, adhesive surface, tape measure.

- Working procedure (after Harman, 2000):Players proceed on Go command from the starting line, with both feet in the same position. Running at full speed to the sideline on the right, touching it with the right hand. The he runs to the left sideline, $9.1 \mathrm{~m}$ away, touching it with the left hand. Afterwards he runs to the starting point where the stopwatch is stopped.Not touching the sidelinesispenalized.

\section{Armspan test}

- Aim: testing explosive force of upper limbs.

- $\quad$ Equipment: smooth surface, tape measure. 
- Working procedure: the athlete rests face down on the arms and toes behind a line, executing three successive bends and stretches of the arms (pushups) with explosion and forward movement. Three successive explosive pushups are carried out only by means of the arms (three successive pushups). Testing is carried out twice. The distance from the starting line to the last landing of the arms is measured.

\section{Results and discussions}

\section{"Pro agility" test (5-10-5)}

Table1.Experimental group-Analysis of statistical-mathematical indices before and after applying the training programme-"Pro agility" test (5-10-5)

\begin{tabular}{|c|c|c|c|c|c|}
\hline Statistical indices & $\mathrm{T}_{\mathrm{i}}$ & $\mathrm{T}_{\mathrm{f}}$ & Statistical indices & \multicolumn{2}{|c|}{$\mathrm{T}_{\mathrm{f}}-\mathrm{T}_{\mathrm{i}}$ differences } \\
\hline Average & 4.56 & 4.37 & Average & & -0.19 \\
\hline Median & 4.51 & 4.36 & Progress & & $4.2 \%$ \\
\hline Std. deviation. & 0.23 & 0.26 & $95 \%$ C.I. & \multicolumn{2}{|c|}{$(-0.21 ;-0.17)$} \\
\hline Minimum & 4.3 & 4.0 & Standard deviation & & 0.04 \\
\hline Maximum & 5.1 & 5.0 & \multirow{2}{*}{ Paired samples T-test } & $\mathrm{t}$ & $\mathrm{p}$ \\
\hline Amplitude & 1 & 1 & & 20.27 & $<0.001$ \\
\hline Coeff. of variation & $5.1 \%$ & $6.0 \%$ & Effect size & & 4.42 \\
\hline
\end{tabular}

In the Pro agility test (5-10-5) for speed in different directions, agility and body control, the elapsed time dropped at the final test, by $0.19 \mathrm{sec}$ on average. Progress was $4.2 \%$. The difference between averages is within the range $(-0.21 ;-0.17)$, with a confidence level of $95 \%$. Data dispersion in both tests is homogeneous. The difference between averages is very high and statistically significant, $\mathrm{p}<0.001$, for $\mathrm{t}=20.27$ and $\mathrm{df}=20$. The average values and the differences between final and initial results are shown in graph1.

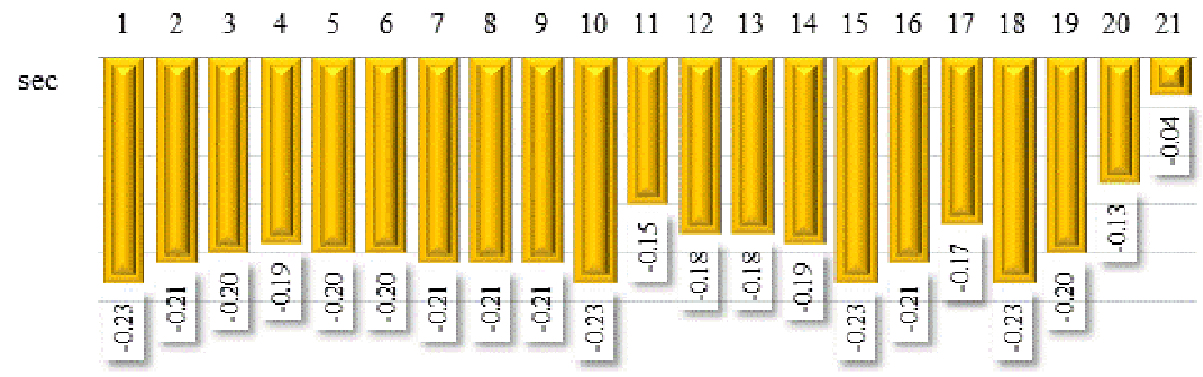

Graph1. Experimental group - Initial and final test - Diferrencesbetween individual final and initial results - "Pro agility”test (5-10-5) 
Table2. Control group-Analysis of statistical-mathematical indices before and after applying the training programme - "Pro agility" test (5-10-5)

\begin{tabular}{|c|c|c|c|c|c|}
\hline Statistical indices & $\mathrm{T}_{\mathrm{i}}$ & $\mathrm{T}_{\mathrm{f}}$ & Statistical indices & \multicolumn{2}{|c|}{$\mathrm{T}_{\mathrm{f}}-\mathrm{T}_{\mathrm{i}}$ differences } \\
\hline Average & 4.98 & 4.87 & Average & & -0.11 \\
\hline Median & 4.97 & 4.86 & Progress & & $2.2 \%$ \\
\hline Std. deviation. & 0.33 & 0.33 & $95 \%$ C.I. & \multicolumn{2}{|c|}{$(-0.12 ;-0.10)$} \\
\hline Minimum & 4.5 & 4.4 & Standard deviation & & 0.02 \\
\hline Maximum & 5.6 & 5.5 & \multirow{2}{*}{ Paired samples T-test } & $\mathrm{t}$ & $\mathrm{p}$ \\
\hline Amplitude & 1 & 1 & & 28.68 & 0.000 \\
\hline Coeff. of variation & $6.6 \%$ & $6.7 \%$ & Effect size & & 6.96 \\
\hline
\end{tabular}

In the Pro agility test (5-10-5) for speed in different directions, agility and body control, the elapsed time dropped at the final test, by $0.11 \mathrm{sec}$ on average. Progress was $2.2 \%$. With a confidence level of $95 \%$, the difference between averages is within the range $(-0.12 ;-0.10)$. Data dispersion in both tests is homogeneous. The difference between averages is high to very high and statistically significant, $\mathrm{p}<0.000$, for $\mathrm{t}=28.68$ and $\mathrm{df}=16$. The average values and the differences between final and initial results are shown in graph 2 .

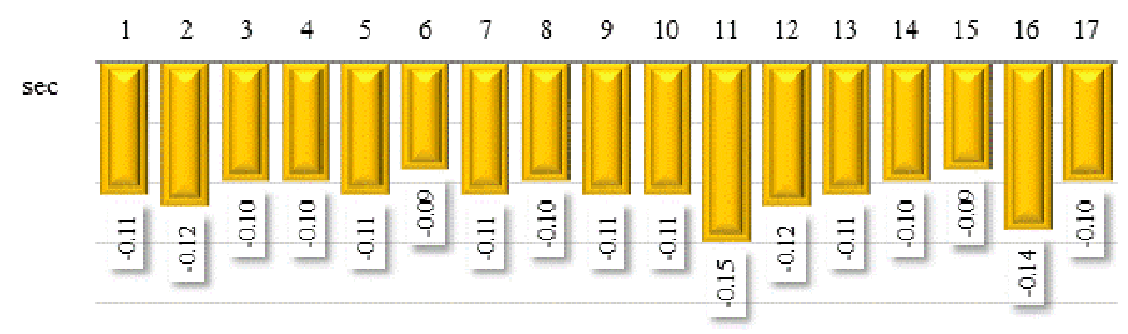

Graph2. Control group -- Initial and final test - Diferrences between individual final and initial results - "Pro agility" test (5-10-5)

Table3. Experimental vs control group-Comparative analysis of the averages of statistical-mathematical indices obtained after the application of the training program - "Pro agility" (5-10-5) test

\begin{tabular}{|c|c|c|c|c|c|c|c|c|}
\hline GROUP & Average & Avg diff. & Med-ian & Std. dev. & Min. & Max. & Ampl-itude & $\begin{array}{c}\text { Coeff. of } \\
\text { var }\end{array}$ \\
\hline $\begin{array}{c}\text { Experi- } \\
\text { mental }\end{array}$ & 4.37 & \multirow{2}{*}{-0.50} & 4.4 & 0.26 & 4.0 & 5.0 & 1.0 & $6.0 \%$ \\
\cline { 1 - 6 } Control & 4.87 & & 4.9 & 0.33 & 4.4 & 5.5 & 1.1 & $6.7 \%$ \\
\hline
\end{tabular}

Table4. Independent T-test - "Pro agility"(5-10-5) test

\begin{tabular}{|c|c|c|c|c|c|c|c|}
\hline \multirow{2}{*}{\multicolumn{2}{|c|}{$\begin{array}{l}\text { Levene's test for equality of } \\
\text { variances }\end{array}$}} & \multirow{3}{*}{$\begin{array}{c}\text { Equal } \\
\text { dispersions? }\end{array}$} & \multicolumn{4}{|c|}{ T-test for equality of averages } & \multirow{3}{*}{ Effect size } \\
\hline & & & \multirow{2}{*}{$\begin{array}{l}\text { Difference of } \\
\text { avgs }\end{array}$} & \multirow{2}{*}{$\mathrm{t}$} & \multirow{2}{*}{ df } & \multirow{2}{*}{$\mathrm{p}$} & \\
\hline $\mathrm{F}$ & Sig. & & & & & & \\
\hline 1.317 & 0.259 & YES & -0.50 & 5.265 & 36 & 0.000 & 1.72 \\
\hline
\end{tabular}


The independent $\mathrm{T}$-test for equal dispersions, with $\mathrm{p}=0.000<0.05$ and $\mathrm{df}=36$, indicate a statistically significant difference between the averages of the results obtained by the subjects of the two groups in the "Pro agility" (5-10-5) test for testing speed in different directions, agility and body control. The average is 4.37 for the experimental group and $4.87 \mathrm{sec}$ for the control group. It follows that the average is lower in the experimental group by $0.50 \mathrm{sec}(10.32 \%)$. The effect size (1.72) shows a high to very high difference between the averages of the two groups. The data dispersion in both tests was homogeneous. The average values of the results of subjects fromboth groups at the final tests are presented in graph 3.

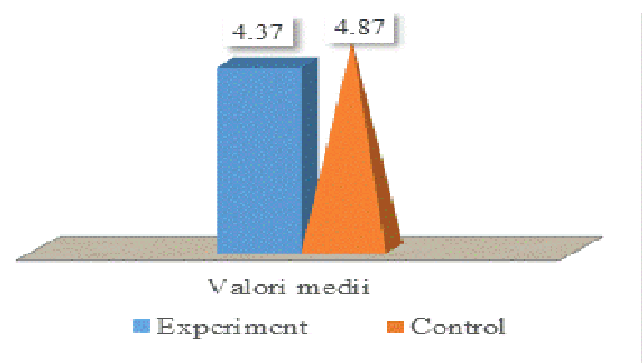

Graph3. Experimental vs control group - Average test values - "Pro agility" (5-10-5) test Armspan test

Table5. Experimental group - Analysis of statistical-mathematical indices before and after applying the training programme-Armspan test

\begin{tabular}{|c|c|c|c|c|c|}
\hline Statistical indices & $\mathrm{T}_{\mathrm{i}}$ & $\mathrm{T}_{\mathrm{f}}$ & Statistical indices & \multicolumn{2}{|c|}{$\mathrm{T}_{\mathrm{f}}-\mathrm{T}_{\mathrm{i}}$ differences } \\
\hline Average & 2.19 & 2.54 & Average & & 0.35 \\
\hline Median & 2.14 & 2.55 & Progress & & $15.9 \%$ \\
\hline Std. deviation. & 0.15 & 0.20 & $95 \%$ C.I. & \multicolumn{2}{|c|}{$(0.32 ; 0.38)$} \\
\hline Minimum & 2.0 & 2.2 & Standard deviation & & 0.06 \\
\hline Maximum & 2.6 & 3.0 & \multirow{2}{*}{ Paired samples T-test } & $\mathrm{t}$ & $\mathrm{p}$ \\
\hline Amplitude & 1 & 1 & & 26.89 & $<0.001$ \\
\hline Coeff. of variation & $6.9 \%$ & $7.9 \%$ & Effect size & & 5.87 \\
\hline
\end{tabular}

The armspan test is used to evaluate explosive force. Armspan increased at the final testing, on average, by $0.35 \mathrm{~cm}$. Progress was $15.9 \%$. With a confidence level of $95 \%$, the difference of averages is within the range $(0.32 ; 0.38)$. For both tests the data dispersion is homogeneous. The difference between averages is very high and statistically significant, $\mathrm{p}<0.001$, with $\mathrm{t}=26.89$ and $\mathrm{df}=20$. The average values and the differences between the final and initial results are shown in graph 4. 
$\mathrm{cm}$

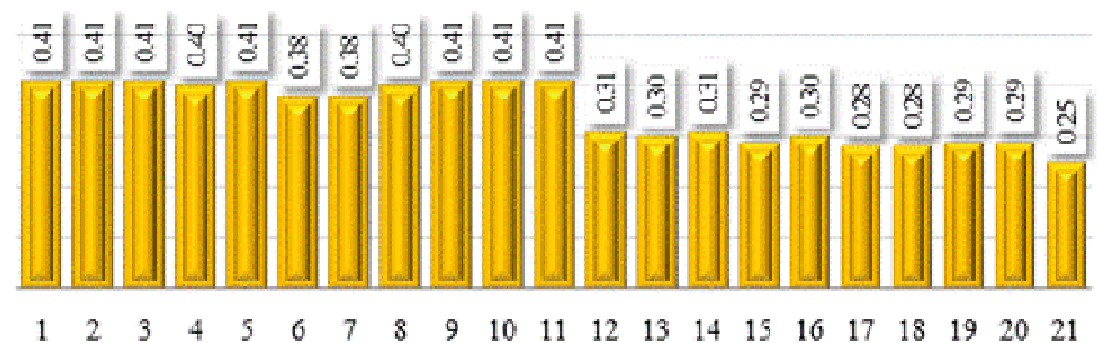

Graph4. Experimental group - Initial and final testing-Difference between individual final and initial results-

Armspan test

Table6.Control group- Analysis of statistical-mathematical indices before and after applying the training programme - Armspan test

\begin{tabular}{|c|c|c|c|c|c|}
\hline Statistical indices & $\mathrm{T}_{\mathrm{i}}$ & $T_{f}$ & Statistical indices & \multicolumn{2}{|c|}{$T_{f}-T_{i}$ differences } \\
\hline Average & 2.14 & 2.24 & Average & & 0.11 \\
\hline Median & 2.15 & 2.24 & Progress & & $5.0 \%$ \\
\hline Std. deviation. & 0.16 & 0.20 & $95 \%$ C.I. & \multicolumn{2}{|c|}{$(0.08 ; 0.13)$} \\
\hline Minimum & 1.8 & 1.9 & Standard deviation & & 0.05 \\
\hline Maximum & 2.3 & 2.5 & \multirow{2}{*}{ Paired samples T-test } & $\mathrm{t}$ & $\mathrm{p}$ \\
\hline Amplitude & 1 & 1 & & 8.40 & 0.000 \\
\hline Coeff. of variation & $7.3 \%$ & $8.8 \%$ & Effect size & & 2.04 \\
\hline
\end{tabular}

The armspan test for evaluating explosive force shows an increase at the final testing, on average, by $0.11 \mathrm{~cm}$. Progress was $5.0 \%$. With a confidence level of $95 \%$, the difference of averages is within the range $(0.08 ; 0.13)$. For both tests the data dispersion is homogeneous. The difference between averages is high to very high and statistically significant, $\mathrm{p}<0.000$, with $\mathrm{t}=8.40$ and $\mathrm{df}=16$. Graph 5 shows the average values and the differences between the final and initial results.

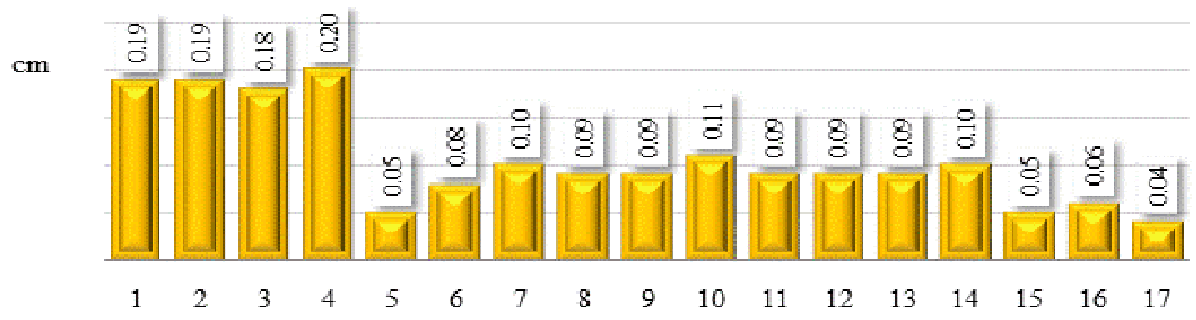

Graph5. Control group - Initial and final testing - Difference between individual final and initial results - Armspan test 
Table7. Experimental vs control group - Comparative analysis of the averages of statistical-mathematical indices obtained after the application of the training program - Armspan test

\begin{tabular}{|c|c|c|c|c|c|c|c|c|}
\hline GROUP & $\begin{array}{c}\text { Avera } \\
\text { ge }\end{array}$ & $\begin{array}{c}\text { Avg } \\
\text { diff. }\end{array}$ & $\begin{array}{c}\text { Med- } \\
\text { ian }\end{array}$ & $\begin{array}{c}\text { Std. } \\
\text { dev. }\end{array}$ & Min. & Max. & $\begin{array}{c}\text { Ampl- } \\
\text { itude }\end{array}$ & $\begin{array}{c}\text { Coeff. } \\
\text { of var }\end{array}$ \\
\hline $\begin{array}{c}\text { Experi- } \\
\text { mental }\end{array}$ & 2.54 & \multirow{2}{*}{0.30} & 2.55 & 0.20 & 2.24 & 2.96 & 0.72 & $7.9 \%$ \\
\cline { 1 - 6 } Control & 2.24 & & 2.24 & 0.20 & 1.85 & 2.53 & 0.68 & $8.8 \%$ \\
\hline
\end{tabular}

Table8. Independent T-test- Armspan test

\begin{tabular}{|c|c|c|c|c|c|c|c|}
\hline \multirow{2}{*}{\multicolumn{2}{|c|}{$\begin{array}{l}\text { Levene's test for equality } \\
\text { ofvariances }\end{array}$}} & \multirow{3}{*}{$\begin{array}{c}\text { Equal } \\
\text { dispersions? }\end{array}$} & \multicolumn{4}{|c|}{ T-test for equality of averages } & \multirow{3}{*}{$\begin{array}{c}\text { Effect } \\
\text { size }\end{array}$} \\
\hline & & & \multirow{2}{*}{ Difference of avgs } & \multirow{2}{*}{$\mathrm{t}$} & \multirow{2}{*}{ df } & \multirow{2}{*}{$\mathrm{p}$} & \\
\hline $\mathrm{F}$ & Sig. & & & & & & \\
\hline 0.305 & 0.584 & YES & 0.30 & 4.620 & 36 & 0.000 & 1.51 \\
\hline
\end{tabular}

At the independent T-test for equal dispersions, with $\mathrm{p}=0.000<0.05$ and $\mathrm{df}=36$, we notice a statistically significant difference between the averages of the results obtained by the subjects of the two groups in the Armspan test for evaluating explosive force. The average is $2.54 \mathrm{~cm}$ for the experimental group and $2.24 \mathrm{~cm}$ for the control group. It follows that the average is higher with the experimental group by $0.30 \mathrm{~cm}(13.41 \%)$. The effect size (1.51) shows a high to very high difference between the averages of the two groups. The data dispersion in both tests was homogeneous. The average values of the results of subjects from both groups at the final tests are presented in graph 6.

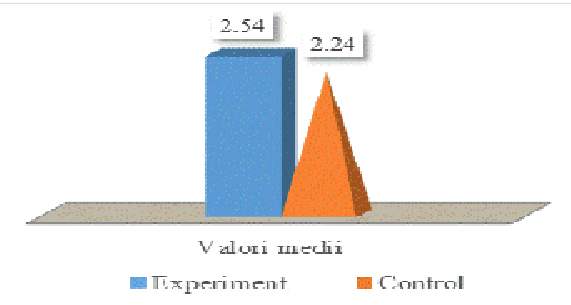

Graph6. Experimental vs control group-Average test values-Armspan test

\section{Conclusion}

Due to the variety of specific methods, means and materials used by us during circuit training during training sessions for male U16 handball players, it is noticeable that they lead to the optimization of technical training by enriching the motor repertoire, the development the coordination skills, strengthening and improving general and specific motor skills, as well as the development of creativity of male U16 handball players. 
Appropriate circuit training methods can lead to more active participation among handball players, as the varied means of action and high attractiveness stimulate their attention, awareness and involvement in the training process. The technical elements of handball such as court movement, holding the ball, passing it, driving or dribbling the ball, shooting on goal through various handball specific technical procedures are combined in circuit training with methods of development of lower and upper limb span, speed, repetition and execution, the main objective being increasing agility, coordination, multidirectional control and the stimulation of creativity, the improvement of individual technique with or without the ball of male U16 handball players.

\section{Bibliography}

1. Blumenstein, B., Lidor, R., Tenenbaum,G.,(2007), Perspective on sport and exercise psychology, Psychology of sport training, Vol 2, pp. 62-77;

2. Cojocari,D., (2014), Recuperarea coordonării şi a echilibrului în activitățile pihomotrice de bază la persoanele după accident vascular cerebral prin tehnici de biofeedback stabilografic, PhD thesis, Chişinău, p. 1429 ;

3. Dumitru, G., (2011), Antrenamentul sportive, Master's course, $2^{\text {nd }}$ semestre, Oradea, p. 8;

4. Esfahankalati, A., Venkatesh, C.,(2013), Relationship between coordinative abilities and performance in elite female handball players, Asian Journal of Multidisciplinary Studies, 1(5), pp. 42-46;

5. Higgs, C. (2010). Physical Literacy - Two approaches, one concept,Physical and health education, 76(1), 67.

6. Hirtz, P., Starosta, W. , 2002), Sensitive and critical periods of motor co-ordination development and its relation to motor learning, Journal of Human Kinetics, 7, pp. 19-28;

7. Riemann, B.L., Lephart, S.M., (2002) The Sensorimotor System, Part II: The Role of Proprioception in Motor Control and Functional Joint Stability, Journal of Athletic Training, 37(1), pp. 80-84;

8. Starosta,W., (2006), The concept of modern training in sport, Physical Culture And Tourism, 13(2), pp. 923 ; 